\title{
THE IMPACTS OF RESIDENTIAL CONSTRUCTION AND PROPERTY PRICES ON RESIDENTIAL CONSTRUCTION OUTPUTS: AN INTER-MARKET EQUILIBRIUM APPROACH
}

\author{
Le MA a, Chunlu LIU*, a, Richard REED ${ }^{\text {a }}$ \\ a Deakin University, 1 Gheringhap Street, Geelong, Victoria 3220, Australia
}

Received 4 December 2015; accepted 16 April 2016

\begin{abstract}
Research into the links between construction output and broader economic development has provided valuable references for inducing theoretical, empirical and policy implications. However, the impact of the construction and property markets on the construction output have not been fully addressed yet. This research argues an inter-market equilibrium between residential construction output and the related markets in terms of construction and property prices. Implementing the panel error correction model, longitudinal data of Australian capital cities is used to identify the inter-market equilibrium and associated dynamic patterns across the observed cities. Subsequently, by comparing the simulated and actual residential construction outputs, the estimated findings are evaluated. The inter-market equilibriums in the Australian capital cities appeared in geographic-spatial clusters while the economy-scale-spatial clusters were observed in dynamic patterns.
\end{abstract}

KEYWORDS: Construction price; Construction output; Panel error correction model; Residential property price

\section{INTRODUCTION}

Residential construction output plays a critical role in the amount of economic progress. An examination of the optimal current and forecast levels of residential construction will assist practitioners and policymakers to undertake effective decision-making and avoid a shortage or excess property market scenario. A positive relationship between the construction output and the aggregate economic development was initially confirmed in earlier studies (Turin 1969; Drewer 1980). In a subsequent study an inverted U shape explained the relationship between construction output and aggregate economic developments (Bon 1992) with more recent studies confirming that the role of construction changes as economic development increases (see Yiu et al. 2004; Ruddock, Lopes 2006; Giang, Pheng 2011; Yorucu 2013; Chiang et al. 2015). However it was demonstrated that reliance on the status of aggregate economy is not always a reliable indicator when undertaking a forecast of future construction output (Wong, Ng 2010).

* Corresponding author. E-mail: chunlu@deakin.edu.au
An innovative approach is to examine the links between the residential construction output and the property sector which together produce intermediate goods and services (Song, Liu 2007). At the same time the property sector relies upon the residential construction sector to meet ongoing demand from population growth, often considered essential when seeking economic development (Chakrabarti, Zhang 2015). The relatively close relationship between construction output and property sector, as well as the variable role of construction output in the aggregate economy, presents a challenge when predicting the appropriate construction output (Chancellor, Abbott 2015). A solution is to examine market mechanisms which could potentially simulate construction output. For example a panel error correction model was used to investigate the relationship between construction output and construction market in Australia with the results confirming the level of construction output is substantially influenced by construction price (Jiang, Liu 2014). A recent study demonstrated the level of construction output is 
linked to construction demand in the construction market where the quantity or volume of production declines when the construction price increases (API 2015). While previous research examined the status of the construction market with reference to construction output, housing economists usually focussed on residential completions or approvals as the proxy for new residential property supply where the relationship between residential output and house prices were confirmed for different countries (Ball et al. 2010; Taltavull de La Paz 2014; Taltavull de La Paz, Gabrielli 2015). Seeking to identify indicators from outside the construction market, Zheng et al. (2012) argued the property market, with reference specifically to house prices, influenced the level of construction output. This conclusion was based on a study of the Hong Kong market where the findings confirmed a positive relationship existed between property prices and construction output.

It is accepted the level of residential construction output is correlated with construction market demand which moves in the opposite direction as construction prices; the aggregate property market output is correlated with residential market supply which moves in the same direction as houses prices. In other words, the appropriate level of residential construction output should respond to the movements in both residential construction and house prices. With reference to a specific level of residential property prices, for example, lower construction prices in the residential construction market can lead to excess residential construction output and an associated waste of both capital and human resources. In turn this can result in a reduction in residential property prices and household wealth, further contributing to a broader economic downturn (Hampson, Brandon 2004). On the other hand, higher residential construction prices may lead to an inadequate level of residential construction output and an inability to provide sufficient accommodation to house the entire population. In turn this can cause problems linked to housing affordability and also restrict economic development (Levin et al. 2009). Therefore it is argued an equilibrium should be established between the residential construction output and the property market to ensure sustained economic growth; however it appears this relationship has been largely ignored to-date.

This research proposes an innovative approach focussing on an inter-market equilibrium in order to simulate changes in residential construction output. By utilising data relating to the residential construction and property markets in Australian capital cities, both the inter-market equilibrium for residential construction output and also the responsiveness of residential construction output to the property markets are specified. It has been demonstrated the level of residential property supply varies according to spatial differences in the market (Ball et al. 2010); therefore a panel error correction model can be implemented to take account for the spatial distinctions across the observed cities. The balance of this paper is organised as follows: the next section discusses the concept of the inter-market equilibrium; the following section introduces the approach of error correction model; the subsequent section presents the description of the data sources; the following section reports the empirical results and the implications; and the final section concludes.

\section{INTER-MARKET EQUILIBRIUM OF RESIDENTIAL CONSTRUCTION OUTPUT}

There are many studies examining short-run and long-run relationships between residential construction output and construction prices from the construction market perspective. For example a linear regression model was used to estimate the long-run elasticity of construction output against construction price between 1974 and 1990; although the significance of output elasticity was observed, the relationship between the output and cost was generally inconsistent (Akintoye et al. 1998). The long-run-causal relationship between construction output and price was also investigated in other studies (see Hillebrandt 2000; Wong, $\mathrm{Ng}$ 2010). In addition to analysing the long-run relationship, attention has also been focussed on the dynamic patterns between the construction output and price where econometric regression models specified the temporal responsiveness of the construction output to construction price dynamics (Hua, Pin 2000; Ng et al. 2004).

From a property market perspective the residential construction output is directly linked to new housing starts or the supply of new residential property. It is accepted the level of residential property prices reflects how well residential property supply is responding to effective demand, where a long-run equilibrium is incorporated in the residential property price level in a well-functioning market (Malpezzi 1999; Malpezzi, Maclennan 2001). It has also been shown that construction output tends to increase with rising residential property prices rather than respond to the actual 
demand, mainly due to the inherent characteristics of residential property as both a consumer and investment good (Glaeser et al. 2008). A recent study in Germany confirmed that new residential property supply was largely driven by the price dynamics with notable differences existing between different geographical areas (Lerbs 2014). Therefore the level of construction output affects the total amount of stock in the residential market, which in turn has a both long-run and short-run relationship with the property market in terms of price.

It can be argued both the construction price and residential property price should influence the construction output; for example the construction price should equal the residential property price where construction output meets new residential property demand perfectly (Mayer, Somerville 2000). Accordingly this research proposes an inter-market equilibrium for the residential construction output where: 1) the construction output is influenced by both construction and residential property markets in terms of price; and 2) when the level of residential property price equals the construction price level, the amount of residential construction output approaches the equilibrium as indicated in Figure 1.

As shown in Figure 1 the residential construction output increases with residential property price growth from the perspective of residential property market, while price decreases are inversely related to construction price increases from the construction market perspective. The inter-market equilibrium of residential construction output, where the residential construction output

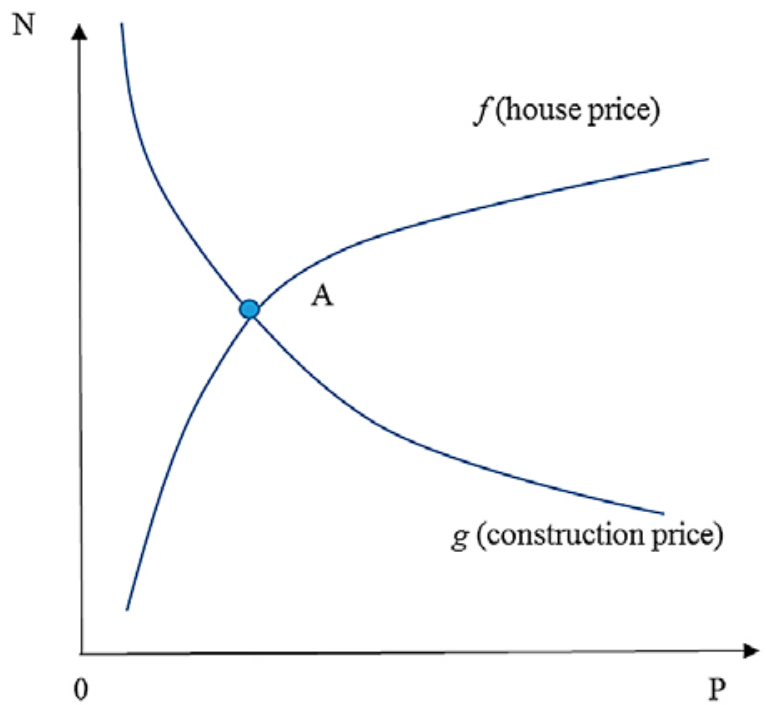

Fig. 1. Inter-market equilibrium for the residential construction output meets new residential property demand, will be achieved as construction and residential property prices approach a certain price level. Residential construction output tends to exceed new residential property demand when the inter-market price level is lower than the equilibrium, while the construction output fails to meet new residential property demand when the price level higher than the equilibrium. Note if the residential construction industry can respond to the inter-market price effectively, then the inter-market price will drive the contemporary construction output whilst fluctuating around the equilibrium. Alternatively if there is an arbitrary barrier in the inter-market, the residential construction output will be higher than new residential property demand when the construction and residential property prices are similar. Therefore in this scenario the inter-market equilibrium does not exist.

Error correction models have been widely used to investigate both the equilibrium and dynamic relationships between economic variables. The equilibrium model estimates long-run relationship between dependent and independent variables in a steady state, while the dynamic model examines the extent to which the dependent variable moves away from the equilibrium caused by changes in the independent variables, as well as movement away from the steady state. Previous research has revealed the regional segmentations of the construction and residential property markets (Ma, Liu 2014a; Ma, Liu 2014b). This research specifies the inter-market equilibrium of the residential construction outputs in Australian capital cities by adapting the framework of the panel error correction model.

\section{DATA DESCRIPTION}

The Australian Bureau of Statistics (ABS) collects longitudinal data relating to construction output, construction price and residential property prices via the quarterly publication Building Activity, Producer Price Indexes and Residential Property Price Indexes. This research uses ABS data for the eight Australian state capital cities on a quarterly basis from the September 2003 to March quarter 2014.

\subsection{Residential construction output}

The analysis uses the number of completed dwelling units as a proxy for the volume of residential construction output. The dwelling unit completion 
number (NO) is estimated from the quarterly Building Activity Survey (ABS 2015a) which records the output of residential construction projects completed each quarter, based on a response rate of approximately $85 \%$ for both buildings and houses completed. The quarterly construction output in the Australian capital cities highlights clear regional differences in scale where the construction output for Brisbane, Melbourne and Sydney were substantially higher in comparison to other cities and equated to $74 \%$ of aggregated dwelling unit completions for all eight capital cities. In contrast the quarterly completions for Canberra, Darwin and Hobart were relatively small and accounted for only $17 \%$ of the total.

\subsection{Residential construction price indexes}

This analysis used the builder's selling price indexes as a measure of residential construction price. The Producer Price Indexes produces indexes for residential building construction and house construction which measure changes in prices recorded by businesses undertaking residential construction between 2011 and 2013 (ABS 2015b). The stated prices are defined as the revenue received by a builder from a purchaser where the tax paid is deducted to produce the net aggregate cost. The building construction price index (BCPI) and the house construction price index (HCPI) recorded a moderate increase over the observation period and across all Australian capital cities. It should be noted the movements of the BCPI are similar to those of the HCPI where the average percentage changes in both the BCPI and HCPI were correspondingly lower in Darwin,
Melbourne, and Sydney, although higher in Perth and Hobart.

\subsection{Residential property price indexes}

The residential property price was provided by the Residential Property Price Indexes (ABS 2015c) where the residential property price indexes (RPPI) are constructed using a stratification approach where the objective is to minimise the physical heterogeneity of dwellings in each stratum. In each period the median price movement is aggregated for each stratum and used to construct a stratumlevel price index. The aggregate index is then calculated by weighting together the individual stratum indexes, where the weights represent the relative significance of the dwelling stock in each stratum. The indexes are initially based on the quarterly residential property prices for established and newly erected dwellings in each capital city between 2011 and 2012 where the RPPI continues to increase across the eight capital cities over this period. The largest percentage changes were observed in Perth (2.3\%) and Hobart (2.0\%) with the smallest change (1.0\%) observed in Adelaide and Darwin.

The quarterly average percentage change in the levels of residential construction output, construction price and residential property prices are shown in Figure 2. The largest percentage change in construction outputs was recorded in Darwin where the changes in construction prices and residential property prices were correspondingly lower. Variations in the construction output, construction price and residential property prices were higher in Perth, although changes in Adelaide, Brisbane, and Sydney were lower.

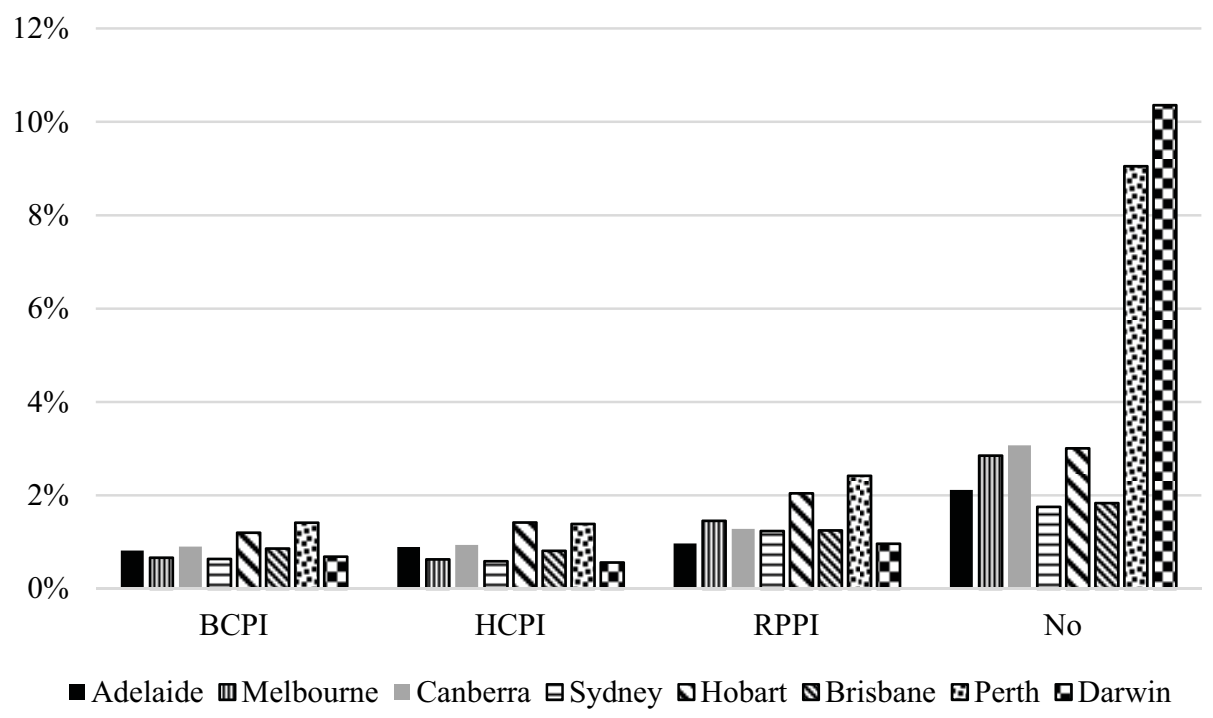

Fig. 2. Quarterly average percentage changes in residential volumes and prices 


\subsection{Unit root tests}

The unit root is a common problem that influences the reliability of time series analysis. In order to investigate the existence of the unit root or stationarity of a time series, this research implements an augmented Dickey-Fuller (ADF) unit root test (Dicky, Fuller 1979). There are three types of hypotheses for the ADF test as follows: (a) strict stationarity, (b) stationarity with an intercept and (c) stationarity with both an intercept and trend. If a time series has strict stationarity then both the mean and variance of the series do not change over time, however if the series has weak stationarity then the covariance of the series does not change over time. Acceptance or rejection of the unit root hypothesis is determined via comparison of the $t$-statistic with specifically derived critical values with the results reported in Table 1.

As seen in Table 1 the acceptance of the unit root hypothesis is confirmed by the p-value of the $t$-statistic for the residential property price, building construction price, house construction price and total dwelling completions. The results confirm there is no individual inter-market equilibrium for these variables. However rejection of the unit root hypothesis is supported by the differences, except for the building construction price and house construction price in Perth. This confirms that changes in the four variables are stable across Australian capital cities. The next section investigates the underlying relationships by examining the data using a panel error correction model.

\section{PANEL ERROR CORRECTION MODEL}

This research used a panel error correction model to account for disparities in residential construction output across regions. The inter-market equilibrium function for construction output in region $\mathrm{i}$ is expressed by Eq. (1):
$N_{._{i t}}=\mathrm{e}+r_{i}+\beta_{i}^{b} B C P I_{i t}+\beta_{i}^{h} H C P I_{i t}+\beta_{i}^{r} R P P I_{i t}+\varepsilon_{i t}$.

Eq. (1) is the inter-market equilibrium equation for construction output and describes stable causal patterns between construction output and prices in the construction and residential property markets. The effects of the aggregate and local economy are represented by e and $r_{i}$ respectively. The long-run elasticity values of building construction price, residential construction price and residential property prices are denoted $\beta_{i}^{b}, \beta_{i}^{h}$ and $\beta_{i}^{r}$ respectively. The error term $\varepsilon_{i t}$ indicates the gap between the inter-market equilibrium estimated construction output and actual construction output. The subscript $i=1,2, \cdots, 8$, indicates one of the observing Australian capital cities. The existence of the estimated inter-market equilibrium is proven if the gap between the estimated and actual construction output is convergent; in other words, if the error term $\varepsilon_{i t}$ is stationary.

Once the inter-market equilibrium is proven to exist, a dynamic equation will be estimated which is expressed as follows:

$$
\begin{aligned}
& \Delta N o_{i t}=c+\tau_{i}+\rho_{i} \varepsilon_{i, t-1}+\theta_{i}^{b} \Delta B C P I_{i t-1}+ \\
& \theta_{i}^{h} \Delta H C P I_{i t-1}+\theta_{i}^{r} \Delta R P P I_{i t-1}+\theta_{i}^{n} \Delta N o_{i t-1}+\mu_{i t}
\end{aligned}
$$

The symbol $\Delta$ indicates changes in the corresponding variable from an observed period to the previous period where the estimate $c+\tau_{i}$ reflects a long-run stable change in construction output which is driven by external factors. The elasticity $\rho_{i}$ shows the speed of the changes in construction output in moving towards the inter-market equilibrium. The elasticity $\theta_{i}^{b}, \theta_{i}^{h}, \theta_{i}^{r}$ and $\theta_{i}^{n}$ indicates the amount of temporal impact on changes in construction output and changes in building construction price, residential construction price, residential property prices and the level of construction output. The term $\mu_{i t}$ is the independent and identically distributed random error. The

\begin{tabular}{|c|c|c|c|c|c|c|c|c|}
\hline \multirow[t]{2}{*}{ City } & \multicolumn{2}{|c|}{ Residential property price } & \multicolumn{2}{|c|}{ Building construction price } & \multicolumn{2}{|c|}{ House construction price } & \multicolumn{2}{|c|}{ Construction output } \\
\hline & Level & Difference & Level & Difference & Level & Difference & Level & Difference \\
\hline Adelaide & 0.983 & 0.006 & 0.993 & 0.002 & 0.993 & 0.002 & 0.454 & 0.000 \\
\hline Brisbane & 0.994 & 0.032 & 0.976 & 0.007 & 1.000 & 0.000 & 0.217 & 0.000 \\
\hline Canberra & 0.966 & 0.000 & 0.995 & 0.004 & 1.000 & 0.001 & 0.713 & 0.000 \\
\hline Darwin & 0.997 & 0.018 & 0.987 & 0.001 & 0.995 & 0.001 & 0.746 & 0.000 \\
\hline Hobart & 1.000 & 0.000 & 0.949 & 0.000 & 1.000 & 0.000 & 0.504 & 0.000 \\
\hline Melbourne & 0.998 & 0.001 & 1.000 & 0.002 & 0.997 & 0.000 & 0.819 & 0.000 \\
\hline Perth & 0.889 & 0.031 & 0.838 & 0.414 & 0.920 & 0.542 & 0.780 & 0.000 \\
\hline Sydney & 0.987 & 0.010 & 0.998 & 0.004 & 1.000 & 0.001 & 0.559 & 0.000 \\
\hline
\end{tabular}

Table 1. P-values of the ADF unit root tests 
dynamic equation shows how the long-run changes in construction output are related to prices. Typically the first three items show the long-run effects on construction output while the last item highlights the temporary impacts. The significant and negative estimate $\rho_{i}$ suggests that long-run changes in construction output result in a stable state; therefore the amount of construction output in the corresponding region should converge with the inter-market equilibrium.

This research uses a seemingly unrelated regression (SUR) estimation to achieve the specification of the panel error correction model, where the model is estimated using the accepted two-step feasible generalised least squares method (Zellner 1962). With this approach the SUR models can produce more efficient estimates when the temporary relationship between construction output across different regions is taken into account.

\section{EMPIRICAL RESULTS}

\subsection{Inter-market equilibrium of residential construction output}

The inter-market equilibrium approach assumes the residential construction outputs are inter-influenced by the residential construction and property markets. Based on data for Australian capital cities the equilibriums are investigated using panel co-integration tests. The equilibrium relationships are estimated based on Equation (1) where the results are reported in Table 2.

The equilibriums are composed of three categories as shown in Table 3, namely: external factors, internal factors and unobserved factors. The external factors reflect influences from the aggregate and local economic environments upon construction output which are captured by the estimated constants. The results confirm all of the influences from the economic environment were statistical- ly significant. The largest elasticity values were observed in Sydney (15.8) and Brisbane (12.4) with the smallest elasticity observed in Canberra $(-5.7)$. This indicates the local residential construction output follows the same direction as the local economy, except for Canberra.

Influences from internal factors are shown by estimates of building construction prices, house construction prices and residential property prices. The elasticity values of building construction prices were negative in Australian capital cities, except for Brisbane and indicates the building construction market is supply-side oriented where higher construction prices reduce the construction output of residential construction. On the other hand, the residential construction market in Brisbane was demand-driven where higher prices attracted increased investment in the industry. The elasticity values of residential construction prices were negative in Adelaide, Brisbane, Darwin, and Perth which indicates the existence of supply-side oriented residential construction markets. In contrast, the elasticity values of house construction prices were positive in Canberra, Hobart, Melbourne, and Sydney suggesting a higher cost associated with residential construction can increase construction output volume. The elasticity values of residential property prices were negative in Melbourne and Sydney, indicating that the property markets in these two cities are supply-side driven, while demand-side driven property markets was evident in the positive elasticity values of residential property prices in the other six cities.

The unobserved factors were captured by the estimation residual series of Equation (1) which reflects the gaps between actual residential construction output and the inter-market equilibrium estimated construction output. If the gaps are stationary, then an inter-market equilibrium existed. The $p$-value of the panel unit roots against the es-

Table 2. Inter-market equilibrium of residential construction output in the Australian capital cities

\begin{tabular}{|c|c|c|c|c|c|c|c|c|c|}
\hline \multirow[t]{2}{*}{ City } & \multicolumn{2}{|c|}{ Aggregate economy } & \multicolumn{2}{|l|}{ BCPI } & \multicolumn{2}{|l|}{ HCPI } & \multicolumn{2}{|l|}{ RPPI } & \multirow{2}{*}{$\begin{array}{l}\text { ADF tests for } \\
\text { the price gap }\end{array}$} \\
\hline & Elasticity & $\mathrm{P}$-value & Elasticity & $\mathrm{P}$-value & Elasticity & $\mathrm{P}$-value & Elasticity & $\mathrm{P}$-value & \\
\hline Adelaide & 9.716 & $0.000 *$ & -0.403 & 0.784 & -0.573 & 0.699 & 0.576 & 0.271 & 0.002 \\
\hline Brisbane & 12.389 & $0.000 *$ & 1.086 & $0.037 *$ & -2.480 & $0.000^{*}$ & 0.656 & 0.212 & 0.000 \\
\hline Canberra & -5.701 & $0.000^{*}$ & -4.906 & $0.049^{*}$ & 6.394 & 0.097 & 1.246 & 0.328 & 0.000 \\
\hline Darwin & 9.386 & $0.000^{*}$ & -1.906 & 0.363 & -1.572 & 0.521 & 2.703 & $0.010^{*}$ & 0.000 \\
\hline Hobart & 3.158 & $0.000 *$ & -2.982 & $0.038^{*}$ & 3.470 & $0.033^{*}$ & 0.237 & 0.733 & 0.002 \\
\hline Melbourne & 1.503 & $0.000 *$ & -2.684 & $0.001^{*}$ & 4.624 & $0.000 *$ & -0.218 & 0.452 & 0.000 \\
\hline Perth & 9.047 & $0.000 *$ & -0.089 & 0.908 & -0.983 & 0.196 & 0.969 & $0.005^{*}$ & 0.013 \\
\hline Sydney & 15.832 & $0.000 *$ & -6.721 & $0.000 *$ & 5.859 & $0.000 *$ & -0.642 & 0.277 & 0.000 \\
\hline
\end{tabular}

Note: * indicates the corresponding estimated correlation coefficient is significant at a $5 \%$ critical level. 
timated residuals are reported in the last column in Table 2. The results confirmed the unit root hypothesis across the Australian capital cities can be rejected and it is evident that inter-market equilibriums exist in residential construction output in the capital cities. The next step is to examine the dynamic patterns of the residential construction output, residential construction prices and property prices.

\subsection{Dynamic patterns between the residential construction output and the markets}

To investigate dynamic patterns of residential construction output a panel ECM was used with estimations reported in Table 3 . The results confirm the amount of elasticity in the economy was not statistically significant in all capital cities at the critical level of $5 \%$; this indicates that longrun changes in residential construction output are influenced by developments in the local and aggregate economy.

The $\mathrm{p}$-values of the $t$-statistic for elasticity indicated elasticity was statistically significant for all capital cities at the critical level of 5\%. The estimated elasticity values of the construction output gaps were negative for all Australian capital cities; therefore long-run changes were driven by price gaps towards the inter-market equilibrium. The elasticity values of the price gaps varied between cities where Darwin had the largest value $(-1.120)$ indicating the largest gap existed between construction output and the property market with the construction output gaps in Brisbane and Canberra were ranked second and third. Adelaide had the smallest elasticity value $(-0.330)$ representing the lowest construction output gap for all Australian capital cities, closely followed by Hobart. The relatively small scale of the elasticity values suggest that long-run growth in the amount of construction output was influenced more by construction output gaps than by regional externalities.

The elasticity values of building construction prices were positive and statistically significant in Brisbane, Hobart, and Melbourne indicating that long-run changes in residential construction output move in the same direction as changes in price. The significant and negative elasticity value in Perth indicated an inverse direction between construction output changes and building construction price changes. The elasticity values associated with house construction prices were significant in Adelaide, Hobart, Melbourne and Perth; positive elasticity was observed in Adelaide and Perth however there was negative elasticity in Hobart and Melbourne. These results suggest that changes in the level of construction output were sensitive to construction price in Adelaide, Brisbane, Hobart, Melbourne and Perth.

Significant elasticity values for residential property prices were only observed in Melbourne and Sydney where both the population sizes and construction-output scales accounted for over a half of the total population and construction output of the eight Australian capital cities; however non-significant elasticity values were observed in the other six capital cities. With globalisation increasing in the residential markets, both Sydney and Melbourne attracted more national and international levels of investment than residential markets in the other Australian capital cities. This is relevant as long-run changes in construction output in Sydney and Melbourne are sensitive to changes in residential property prices. This finding aligns with the argument that residential construction output tends to respond to residential

Table 3. The effects of the price dynamics on the residential construction output changes in the Australian capital cities

\begin{tabular}{|c|c|c|c|c|c|c|c|c|c|c|c|c|}
\hline \multirow[t]{2}{*}{ City } & \multicolumn{2}{|c|}{$\begin{array}{l}\text { Regional } \\
\text { effects }\end{array}$} & \multicolumn{2}{|c|}{$\begin{array}{l}\text { Construction } \\
\text { output gap }\end{array}$} & \multicolumn{2}{|c|}{$\begin{array}{l}\text { Change in } \\
\text { BCPI }\end{array}$} & \multicolumn{2}{|c|}{$\begin{array}{l}\text { Change in } \\
\text { HCPI }\end{array}$} & \multicolumn{2}{|c|}{$\begin{array}{l}\text { Change in } \\
\text { RPPI }\end{array}$} & \multicolumn{2}{|c|}{$\begin{array}{l}\text { Change in con- } \\
\text { struction output }\end{array}$} \\
\hline & $\begin{array}{l}\text { Elastic- } \\
\text { ity }\end{array}$ & $\mathrm{P}$ & $\begin{array}{l}\text { Elastic- } \\
\text { ity }\end{array}$ & ue & $\begin{array}{l}\text { Elastic- } \\
\text { ity }\end{array}$ & $\mathrm{P}-\mathrm{v}$ & $\begin{array}{l}\text { Elastic- } \\
\text { ity }\end{array}$ & $\mathrm{P}-\mathrm{v}$ & $\begin{array}{l}\text { Elastic- } \\
\text { ity }\end{array}$ & ue & $\begin{array}{l}\text { Elastic- } \\
\text { ity }\end{array}$ & ue \\
\hline Adelaide & -0.015 & 0. & -0.330 & $0.011^{*}$ & -0.0 & 271 & (5) & 0. & 31 & 1 & 30 & 0.0 \\
\hline Brisbane & -0.037 & 0.639 & -1.052 & $0.000 *$ & 3.078 & $0.045^{*}$ & 1.795 & 0.345 & -1.375 & 0.104 & -0.149 & 0.115 \\
\hline Canberra & 0.104 & 0.639 & -0.819 & $0.000 *$ & -9.709 & 0.192 & -0.615 & 0.934 & -3.115 & 0.154 & -0.130 & 0.362 \\
\hline Darwin & -0.070 & 0.639 & -1.120 & $0.000 *$ & 74 & 0.526 & 4.145 & 0.070 & -1.173 & & 0.263 & 0.057 \\
\hline Hobart & -0.012 & 0.639 & -0.353 & $0.017^{*}$ & 6.951 & & -5.227 & & -0.956 & & & 0.437 \\
\hline Melbourne & 0.018 & 0.639 & -0.789 & $0.000^{*}$ & 3.992 & $0.004^{*}$ & -3.368 & $0.015^{*}$ & -1.578 & $0.007^{*}$ & -0.209 & $0.044^{*}$ \\
\hline Perth & -0.034 & 0.639 & -0.866 & $0.000 *$ & -6.610 & $0.029 *$ & 9.374 & $0.005^{*}$ & -0.642 & 0.339 & -0.205 & 0.117 \\
\hline Sydney & -0.016 & 0.639 & -0.783 & $0.000 *$ & 3.377 & 0.146 & 0.580 & 0.841 & -2.213 & $0.016^{*}$ & -0.013 & 0.922 \\
\hline
\end{tabular}

Note: * indicates the corresponding estimated correlation coefficient is significant at a $5 \%$ critical level. 
property prices rather than responding to the actual demand, primarily due to the inherent characteristics of residential property as an investment (Glaeser et al. 2008).

The elasticity values associated with changes in construction output were negative and statistically significant in Adelaide and Melbourne and indicates that temporary changes in the level of regional construction output negatively influenced long-run growth. Since the construction output gaps, changes in building and house construction prices, changes in residential property prices and changes in residential construction output are stationary from a long-run perspective, these factors do not have a permanent influence on long-run changes in construction output. The amount of influence diminishes as construction output approaches an inter-market equilibrium.

\section{PREDICTION OF RESIDENTIAL CONSTRUCTION OUTPUT}

The models were used to forecast the level of construction output in the Australian capital cities. Based on quarterly data from December 2013 to March 2014, the residential construction output was based on the forecast values with the actual values are presented in Figure 3.
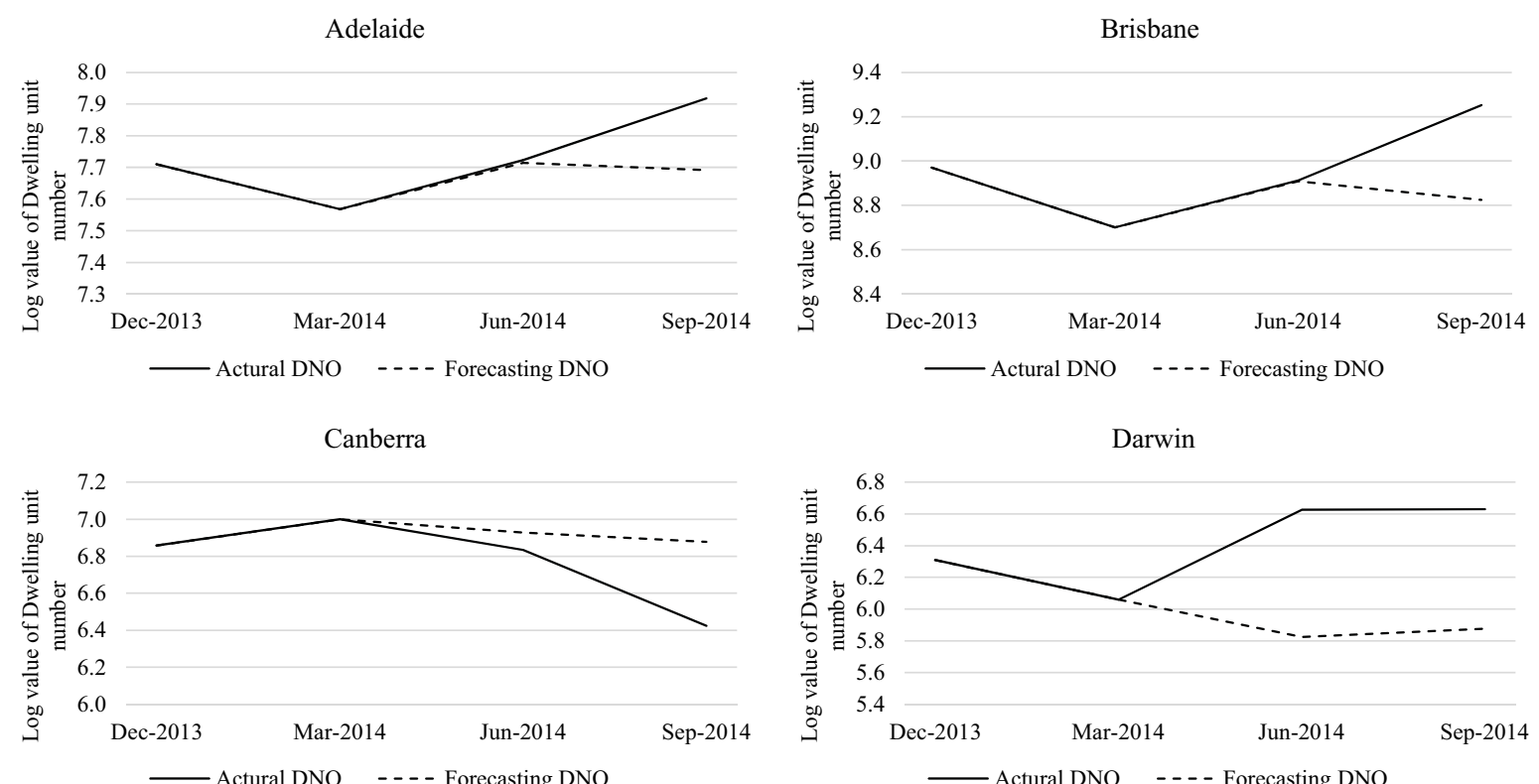

Hobart

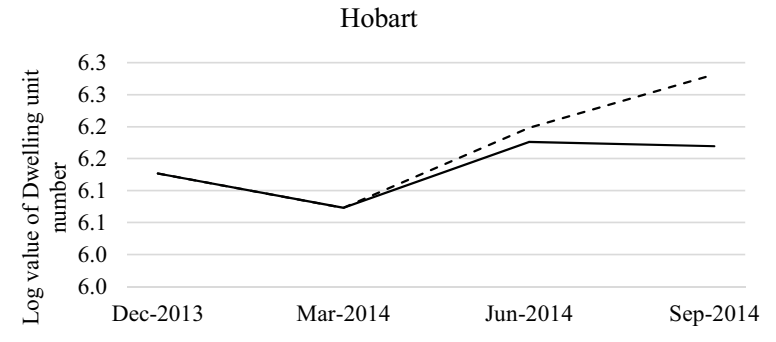

— Actural DNO - - - - Forecasting DNO

Perth
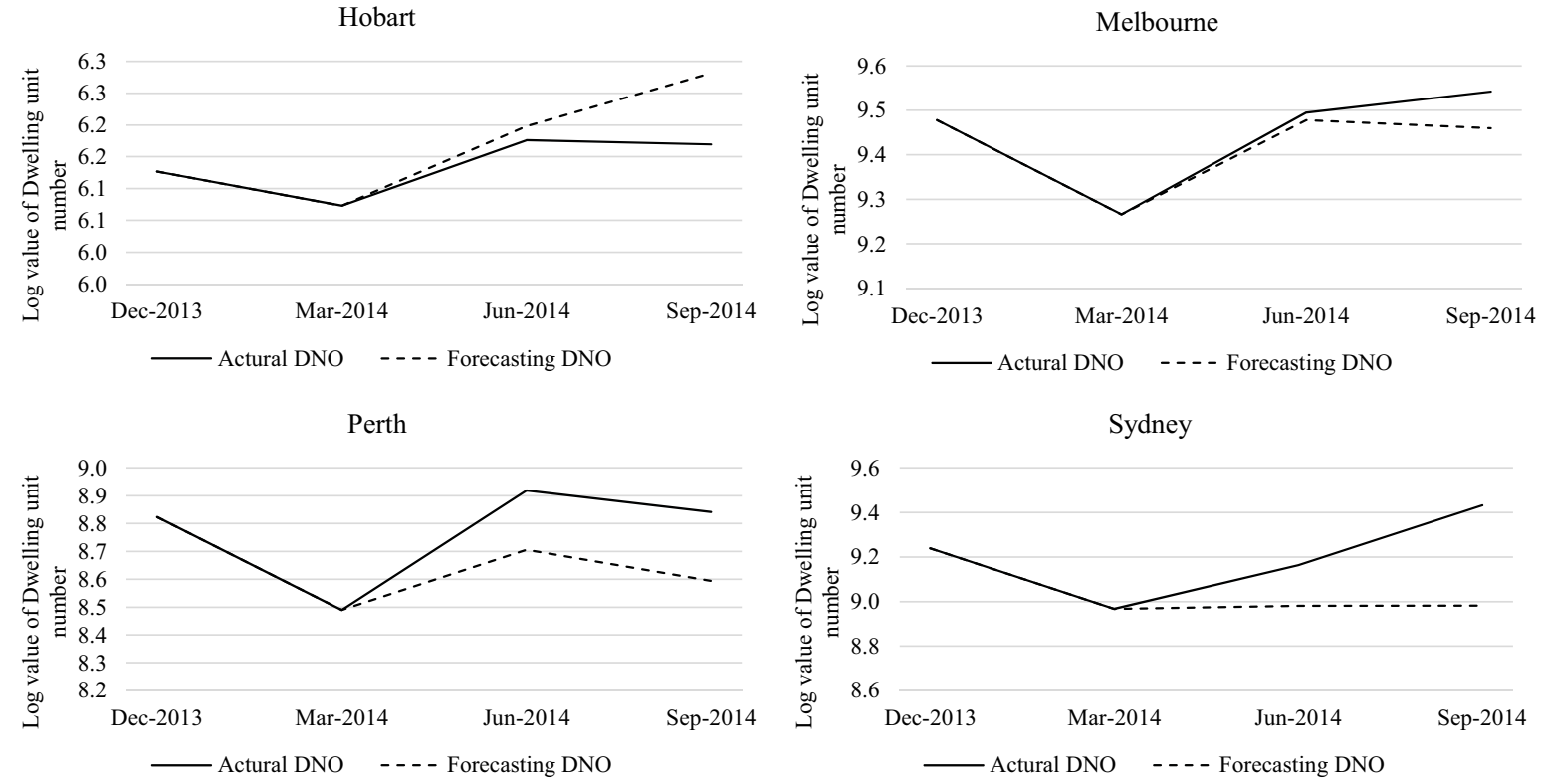

Fig. 3. Prediction of the residential construction output 
In Figure 3 the actual construction output was lower than forecast for Canberra and Hobart which indicates actual construction output in these two cities had not reached the inter-market equilibrium; this may be linked to an insufficient residential supply in both the construction and property markets. In comparison the actual construction output exceeded the forecast level in the remaining six cities. This finding suggests there will be future declines in local residential construction output unless external changes are undertaken to maintain higher construction output levels in these regions.

To evaluate the simulation accuracy of the endogenous growth model we then compared the simulated amount of construction output against the actual amount of construction output. The model used the mean absolute percentage error (MAPE) to reflect the accuracy of the simulated amount of construction output. The MAPE was calculated as follows:

$$
M A P E=\frac{1}{T} \times \sum_{t=1}^{T} \frac{\left|\theta_{t}\right|}{p_{t}} \times 100,
$$

where: $\theta_{t}=\widetilde{p_{t}}-p_{t}$ is the error term between the simulated amount of construction output $\widetilde{p}_{t}$ and the actual amount of construction output $p_{t}$ at time $t ; T$ is the total number of simulation periods. The results relating to the accuracy of the simulated regional volumes of construction output is reported in Table 4.

The mean average percentage error was less than $5 \%$ in the forecast results for all capital cities with the exception of Darwin. The absolute percentage errors in the first forecast sub-period were less than $2.5 \%$ for most capital cities however the absolute percentage errors were larger during the second forecast period, especially for Canberra (7.09\%). The absolute percentage errors for Darwin were comparatively larger over the first and second forecast periods, being $12.12 \%$ and $11.36 \%$ respectively. These results confirm the inter-market equilibrium model can produce accurate simulations for residential construction output, especially over a specific time period. However the model appears less efficient in explaining the patterns between construction output and the inter-market equilibrium for cities such as Darwin; arguably this is linked to differences with other capital cities including the remote locations, social systems, and property and land tenure policies.

\section{CONCLUSIONS}

Developing a simulation model for construction output has been an important research objective for policy formulation and implementation when considering the importance and impact of the construction industry to the national economy. Analogous to the market mechanism and the interconnections between construction and property markets, this research proposed an innovative inter-market equilibrium approach to simulate the residential construction output in Australian capital cities. A panel error correction model identified the existence of the inter-market equilibrium from a long-run perspective; it also examined the shortrun dynamic patterns between construction output and dynamics in both construction and property markets. The empirical evidence supports the hypothesis against the inter-market equilibrium of the residential construction output across the observed cities. More specifically, the inter-market equilibrium of the residential construction output are significantly determined by the broader economic market while the inter-market influences vary between each city.

It has been shown that local economic development creates higher residential construction output in the Australian capital cities from a longrun perspective, with the exception of Canberra. In other words the residential construction industry advocates that strong local economic development will create additional employment and increase immigration in most Australian capital cities, especially Sydney and Brisbane. In contrast the influence from the local economy upon residential construction development in Canberra is not as strong, therefore indicating that external factors in Canberra are unique; this includes the unique economic environment and the high proportion of government employees which both play a role as a filter in residential construction development from a long-run perspective.

Table 4. The accuracy of the inter-market equilibrium model predictions

\begin{tabular}{lllllllll}
\hline Forecasting period & Adelaide & Brisbane & Canberra & Darwin & Hobart & Melbourne & Perth & Sydney \\
\hline Jun-14 & $0.11 \%$ & $0.04 \%$ & $1.37 \%$ & $12.12 \%$ & $0.36 \%$ & $0.18 \%$ & $2.39 \%$ & $1.99 \%$ \\
Sep-14 & $2.86 \%$ & $4.63 \%$ & $7.09 \%$ & $11.36 \%$ & $1.82 \%$ & $0.87 \%$ & $2.80 \%$ & $4.76 \%$ \\
MAPE & $1.49 \%$ & $2.33 \%$ & $4.23 \%$ & $11.74 \%$ & $1.09 \%$ & $0.52 \%$ & $2.59 \%$ & $3.37 \%$ \\
\hline
\end{tabular}


The inter-market equilibrium types can be classified into four categories: (1) the residential-demand determined equilibrium; for example where the construction output are determined positively by the local residential property price levels as observed in Perth and Darwin; (2) the construction-demand determined equilibrium; for example where the construction output are positively determined by the aggregate local construction markets as observed in Melbourne and Hobart; (3) the construction-supply determined equilibrium; for example where the construction outputs are negatively dependent on the aggregate construction markets as observed in Sydney, Brisbane and Canberra; and (4) the economy determined equilibrium; for example where the residential construction output is nether influenced by the construction nor the residential markets significantly as observed in Adelaide.

Finally, the dynamic patterns highlighted the contemporary responsiveness of the residential construction outputs to the fluctuations in markets in each city. The changes in the residential construction output in Canberra and Darwin were mainly caused by gaps from the inter-market equilibriums; the residential construction output changes in Adelaide, Brisbane, Perth and Hobart were determined by the construction-market dynamics; and changes in residential construction output in Melbourne and Sydney tended to be dominated by the dynamics in the residentialproperty market.

\section{REFERENCES}

ABS. 2015a. Building activity. Cal No.: 8752.0. Canberra: Australian Bureau of Statistics.

ABS. 2015b. Producer price indexes. Cal No.: 6427.0. Canberra: Australian Bureau of Statistics.

ABS. 2015c. Residential property price indexes: eight capital cities. Cal No.: 6416.0. Canberra: Australian Bureau of Statistics.

Akintoye, A.; Bowen, P.; Hardcastle, C. 1998. Macro-economic leading indicators of construction contract prices, Construction Management and Economics 16(2): 159-175. https://doi.org/10.1080/014461998372466

API. 2015. Valuation of real estate. Canberra: Australian Property Institute.

Ball, M.; Meen, G.; Nygaard, C. 2010. Housing supply price elasticities revisited: evidence from international, national, local and company data, Journal of Housing Economics 19(4): 255-268. https://doi.org/10.1016/j.jhe.2010.09.004

Bon, R. 1992. The future of international construction: secular patterns of growth and decline, Habitat International 16(3): 119-128.

https://doi.org/10.1016/0197-3975(92)90068-A
Chakrabarti, R.; Zhang, J. 2015. Unaffordable housing and local employment growth: evidence from California municipalities, Urban Studies 52(6): 1134-1151. https://doi.org/10.1177/0042098014532854

Chancellor, W.; Abbott, M. 2015. The Australian construction industry: is the shadow economy distorting productivity?, Construction Management and Economics 33(3): 176-186. https://doi.org/10.1080/0 1446193.2015.1028954

Chiang, Y. H.; Tao, L.; Wong, F. K. W. 2015. Causal relationship between construction activities, employment and GDP: the case of Hong Kong, Habitat International 46: 1-12. https://doi.org/10.1016/j.habitatint.2014.10.016

Dicky, D. A.; Fuller, W. A. 1979. Distribution of the estimators for autoregressive time series with a unit root, Journal of the American Statistical Association 74: 427-431.

Drewer, S. 1980. Construction and development: a new perspective, Habitat International 5(3-4): 395-428. https://doi.org/10.1016/0197-3975(80)90028-4

Giang, D. T. H.; Pheng, L. S. 2011. Role of construction in economic development: review of key concepts in the past 40 years, Habitat International 35(1): 118125. https://doi.org/10.1016/j.habitatint.2010.06.003

Glaeser, E. L.; Gyourko, J.; Saiz, A. 2008. Housing supply and housing bubbles, Journal of Urban Economics 64(2): 198-217. https://doi.org/10.1016/j. jue.2008.07.007

Hampson, K.; Brandon, P. 2004. Construction 2020: a vision for Australia's property and construction industry. Brisbane: Cooperative Research Centre for Construction Innovation.

Hillebrandt, P. 2000. Economic theory and the construction industry. $3^{\text {rd }}$ ed. Palgrave Macmillan UK.

Hua, G. B.; Pin, T. H. 2000. Forecasting construction industry demand, price and productivity in Singapore: the Box-Jenkins approach, Construction Management and Economics 18(5): 607-618. https://doi.org/10.1080/014461900407419

Jiang, H.; Liu, C. 2014. A panel vector error correction approach to forecasting demand in regional construction markets, Construction Management and Economics 32(12): 1205-1221. https://doi.org/10.1080/0 1446193.2014 .977800

Lerbs, O. W. 2014. House prices, housing development costs, and the supply of new single-family housing in German counties and cities, Journal of Property Research 31(3): 183-210. https://doi.org/10.1080/095 99916.2014 .893249

Levin, E.; Montagnoli, A.; Wright, R. E. 2009. Demographic change and the housing market: evidence from a comparison of Scotland and England, Urban Studies 46(1): 27-43.

https://doi.org/10.1177/0042098008098635

Ma, L.; Liu, C. 2014a. Did the late-2000s financial crisis influence construction labour productivity?, Construction Management and Economics 32(10): 10301047. https://doi.org/10.1080/01446193.2014.944927

Ma, L.; Liu, C. 2014b. Do spatial effects drive house prices away from the long-run equilibrium?, Pacific Rim Property Research Journal 20(1): 13-29. https://doi.org/10.1080/14445921.2014.11104384 
Malpezzi, S. 1999. A simple error correction model of house prices, Journal of Housing Economics 8(1): 27-62. https://doi.org/10.1006/jhec.1999.0240

Malpezzi, S.; Maclennan, D. 2001. The long-run price elasticity of supply of new residential construction in the United States and the United Kingdom, Journal of Housing Economics 10(3): 278-306. https://doi.org/10.1006/jhec.2001.0288

Mayer, C. J.; Somerville, C. T. 2000. Residential construction: using the urban growth model to estimate housing supply, Journal of Urban Economics 48(1): 85-109. https://doi.org/10.1006/juec.1999.2158

Ng, S. T.; Cheung, S. O.; Skitmore, M.; Wong, T. C. Y. 2004. An integrated regression analysis and time series model for construction tender price index forecasting, Construction Management and Economics 22(5): 483-493. https://doi.org/10.1080/0144619042000202799

Ruddock, L.; Lopes, J. 2006. The construction sector and economic development: the Bon curve, Construction Management and Economics 24(7): 717-723. https://doi.org/10.1080/01446190500435218

Song, Y.; Liu, C. 2007. An input-output approach for measuring real estate sector linkages, Journal of Property Research 24(1): 71-91. https://doi.org/10.1080/09599910701297697

Taltavull de La Paz, P. 2014. New housing supply and price reactions: evidence from Spanish markets, Journal of European Real Estate Research 7(1): 4-28. https://doi.org/10.1108/JERER-10-2013-0023

Taltavull de La Paz, P.; Gabrielli, L. 2015. Housing supply and price reactions: a comparison approach to
Spanish and Italian markets, Housing Studies 30(7): 1036-1063. https://doi.org/10.1080/02673037.2015.10 06183

Turin, D. A. 1969. The construction industry: its economic significance and its role in development. London: University College, Environmental Research Group.

Wong, J. M. W.; Ng, S. T. 2010. Forecasting construction tender price index in Hong Kong using vector error correction model, Construction Management and Economics 28(12): 1255-1268. https://doi.org/10.1080/01446193.2010.487536

Yiu, C. Y.; Lu, X. H.; Leung, M. Y.; Jin, W. X. 2004. A longitudinal analysis on the relationship between construction output and GDP in Hong Kong, Construction Management and Economics 22(4): 339345. https://doi.org/10.1080/0144619042000176465

Yorucu, V. 2013. Construction in an open economy: autoregressive distributed lag modeling approach and causality analysis - case of North Cyprus, Journal of Construction Engineering and Management 139(9): 1199-1210. https://doi.org/10.1061/(ASCE)CO.19437862.0000714

Zellner, A. 1962. An efficient method of estimating seemingly unrelated regressions and tests for aggregation bias, Journal of American Statistics Association 57(298): 348-368. https://doi.org/10.1080/01621459.1 962.10480664

Zheng, X.; Chau, K. W.; Hui, E. C. M. 2012. The impact of property price on construction output, Construction Management and Economics 30(12): 1025-1037. https://doi.org/10.1080/01446193.2012.714872 